\title{
PRODUKTIVITAS TANAMAN CABAI RAWIT (Capsicum frutescens L.) MELALUI PEMBERIAN PUPUK ORGANIK BERBAHAN DASAR Hydrilla verticillata L. DAN KOTORAN AYAM
}

\author{
Benediktus Ege1 ${ }^{1}$ Hendrikus Julung² \\ 1,2 Program Studi Pendidikan Biologi, STKIP Persada Khatulistiwa Sintang, Sintang \\ e-mail: ${ }^{1}$ ama_tamo@yahoo.com, ${ }^{2}$ henjulung@gmail.com \\ Manuscript recieved:30-07-2019 Revision Accepted: 14-11-2019
}

\begin{abstract}
Abstrak
Hydrilla veriticillata L., merupakan salah satu tumbuhan air yang banyak ditemukan di perairan tergenang seperti sawah dan rawa rawa. Kotoran ayam merupakan limbah yang dihasilkan dari peternakan ayam yang dapat menimbulkan masalah bagi lingkungan. Kedua bahan tersebut mengandung beberapa unsur hara sehingga berpotensi untuk dijadikan sebagai pupuk. Tujuan penelitian ini adalam mengetahui pengaruh pupuk organik berbahan dasar Hydrilla verticillata L., dan kotoran ayam terhadap pertumbuhan dan produktivitas tanaman cabai rawit (Capsicum frutescens L.). Penelitian ini menggunakan Rancangan Acak Lengkap (RAL) dengan lima perlakuan pupuk organik berbahan dasar Hydrilla verticillata dan kotoran ayam dengan diulang sebanyak 5 kali pada masing-masing perlakuan. Hasil analisis sidik ragam variabel produktivitas menunjukan $f_{\text {hitung }}>f_{\text {tabel }}$ dimana berat basah buah cabai rawit (Capsicum frutescens L.) adalah 10,6>2,67. Selanjutnya, hasil uji BNJ menunjukkan bahwa perlakuan ke 5 (500 gram) merupakan perlakuan paling baik untuk produktivitas tanaman cabai rawit (Capsicum frutescens $\mathrm{L}$ ). Disimpulkan bahwa produktivitas tanaman cabai rawit (Capsicum frutescens L.) signifikan dipengaruhi oleh pupuk organik berbahan dasar Hydrilla verticillata dan kotoran ayam.
\end{abstract}

Kata Kunci : Produktivitas, Tanaman cabai rawi, Hydrilla verticillata L, kotoran ayam,

\section{Abstract}

Hydrilla veriticillata $\mathrm{L}$. , is one that many aquatic plants found growing in the stagnant waters such as rice fields and marshes. Chicken manure is a waste produced from chicken farms that can cause problems for the environment. Both of these ingredients contain several nutrients so that have the potential to be used as fertilizer.The purpose of this study was to find out the effect of organic fertilizer made of Hydrillaverticillata and chicken manure toward the growth and productivity of cayenne pepper (Capsicum frutescens L.) This study used a completely randomized design (CRD) with five treatment organic fertilizer made from Hydrilla verticillata L., and chicken manure with repeated 5 times in each treatment. The results of the variance analysis productivity variable showed that $\mathrm{f}_{\text {count }}>\mathrm{f}_{\text {tabel }}$ where the wet weight of cayenne pepper (capsicum frutescens $\mathrm{L}$.) is 10.6>2.67. Furthermore, the BNJ test results showed that the 5 th treatment ( 500 grams) was the best treatment for the productivity of cayenne pepper (Capsicum frutescens L.). It was concluded that productivity of cayenne papper (Capsicum frutescens L.) significantly affected by organic fertilizers made of Hydrilla verticillata and chicken manure.

Keywords: productivity, cayenne pepper, organic fertilizer, hydrilla verticillata l, chicken manure 


\section{PENDAHULUAN}

Cabai rawit (Capsicum frutescens L.) merupakan salah satu tanaman hortikultura dari famili Solanaceae yang memiliki banyak kandungan vitamin A,B,C. dan kandungan zat lain seperti kapsaisin, kapsantin, karotenid, alkaloid, resin, dan minyak atsiri (Umah, 2012). Cabai rawit merupakan salah satu jenis tanaman hortikultura penting di indonesia yang dibudidayakan secara komersial (Darmawan, 2014). Cabai rawit juga memiliki nilai ekonomi yang tinggi karena kebutuhan akan cabai rawit semakin meningkat seiring dengan beragamnya jenis dan menu masakan yang menggunakan cabai rawit. Rata-rata konsumsi cabai rawit cukup tinggi sekitar 0,035ons/Minggu/Kapita selama tahun 2018 (BPS, 2019). Pada dasawarsa ini cabai rawit merupakan komoditas unggulan diantara 18 jenis sayuran komersial yang dibudidayakan di Indonesia walaupun harga cabai rawit tersebut selalu mengalami fluktuasi harga yang tajam di pasaran. Tingginya kebutuhan masyarakat akan tanaman cabai rawit tentunya meningkatkan minat petani untuk memproduksi tanaman cabai rawit yang melimpah dalam waktu yang cepat. Namun yang menjadi permasalahan saat ini adalah masih banyak petani yang bergantung pada penggunaan produk pupuk kimia dalam upaya meningkatan produksi cabai rawit.

Pupuk kimia adalah pupuk yang dibuat oleh perusahaan-perusahaan dengan menggunakan zat-zat kimia. Penggunaan pupuk kimia dalam rangka meningkatkan kuantitas dan kualitas produksi pertanian selain memberikan dampak baik ternyata dapat memberikan dampak buruk bagi tanah dan tanaman. Bahan-bahan kimia baik sebagai pembasmi hama (insektisida) maupun pupuk (fertilizer) pada akhirnya akan menyumbang pencemar lingkungan. Selain itu, penggunan pupuk kimia yang terus-menerus diaplikasikan ke tanaman dalam jangka waktu yang panjang akan mempercepat hilangnya zat-zat organik dan kesimbangan zat makanan di dalam tanah sehingga tanah menjadi tandus, keras dan tidak dapat digunakan untuk budidaya tanaman lagi. Hingga kini pupuk kimia masih menjadi andalan dikalangan para petani karena para petani ingin menghemat pengeluaran dalam kegiatan pertaniannya. Berdasarkan kenyataan tersebut perlu adanya upaya untuk memproduksi tanaman atau sayuran yang bebas dari bahan kimia. Hal ini dapat dilakukan dengan pengolahan yang intensif yang diikuti dengan usaha perbaikan sifat fisik, sifat kimia tanah serta penyediaan hara tanaman melalui pemupukan menggunakan pupuk organik pada media tumbuh tanaman. Pada prinsipnya suatu media tumbuh harus mempunyai empat fungsi pokok untuk memberikan pertumbuhan yang baik bagi tanaman, yaitu harus dapat menahan air yang tersedia, menyimpan hara bagi tanaman, menunjang tanaman dan mempunyai aerasi yang baik (Kusumawati, 2016).

Pupuk organik merupakan pupuk yang berasal dari sisa tanaman, hewan atau manusia seperti pupuk kandang, pupuk hijau, dan kompos yang berbentuk cair maupun padat. Selain mudah dibuat sendiri dengan modal pembuatan yang murah, penggunaan pupuk organik juga menguntungkan bagi lingkungan, tanah dan tanaman karena pupuk organik dapat memperbaiki sifat-sifat tanah seperti sifat fisik, kimia dan biologi (Simanungkalit, 2006). Salah satu pupuk organik yang sering digunakan dalam pertanian adalah pupuk kompos. Bahan yang dapat dimanfaatkan untuk pembuatan kompos adalah sampah kota, sampah sayuran, sisa hasil pertanian, sisa industri kayu, limbah pabrik gula kotoran hewan, limbah kertas dan berbagai jenis gulma. Suwahyono (2014: 20) Salah satu jenis gulma yang dapat dimanfaatkan untuk kompos adalalah gulma air Hydrilla verticillata L.

Hydrilla verticillata L., adalah tanaman yang selalu hidup di perairan, seperti danau, kolam dan rawa. Hydrilla sering disebut sebagai gulma karena pertumbuhan Hydrilla sering tidak 
terkendali dan dapat memadati permukaan perairan dalam waktu yang cepat. Populasi H.verticillata L., yang terlalu besar menyebabkan air sulit mengalir dan berpotensi menjadi banjir. Selain itu tumbuhan H.verticillata L., dapat menghambat pertumbuhan organisme lain di dalam perairan, karena H.verticillata L., menutupi permukaan air sehingga menyebabkan sinar matahari sulit untuk menembus perairan dan kadar oksigen menjadi berkurang. Perkembangbiakan H.verticillata L., terjadi sangat pesat dengan adanya stolon sehingga dapat mencemari perairan dan mengganggu laju aliran air (Marwan, 2017: 3). Perlu dilakukannya penanganan yang tepat terhadap tanaman H.verticillata L., tersebut salah satunya dengan memanfaatkan H.verticillata L., sebagai pupuk kompos. H.verticillata L., yang dijadikan sebagai bahan pupuk kompos, akan semakin baik jika dikombinasikan dengan pupuk kandang. Salah satu pupuk kandang yang dapat digunakan adalah kotoran ayam.

Kotoran ayam merupakan limbah yang dihasilkan dari peternakan ayam yang dapat menimbulkan masalah bagi lingkungan. Kotoran ayam memiliki potensi yang besar sebagai pupuk organik. Penggunaan bahan organik kotoran ayam mempunyai beberapa keuntungan antara lain sebagai pemasok hara tanah dan meningkatkan retensi air. Apabila kandungan air tanah meningkat, proses perombakan bahan organik akan banyak menghasilkan asam-asam organik. Anion dari asam organik dapat mendesak fosfat yang terikat oleh Fe dan Al sehingga fosfat dapat terlepas dan tersedia bagi tanaman. Penambahan kotoran ayam berpengaruh positif pada tanah masam berkadar bahan organik rendah karena pupuk organik mampu meningkatkan kadar P, K, Ca, dan Mg pada tanah. Suwahyono (2014: 13-14) rata-rata kandungan unsur hara dari kotoran ayam sebesar 10,95 ton/tahun yaitu Nitrogen (25kg/ton), Fosfor (11 Kg/ton), Kalium (10 Kg/ton), Kalsium (36 Kg/ton), Magnesium (6 Kg/ton), Sulfur $(3,2 \mathrm{Kg} /$ ton $)$, Besi $(2,3 \mathrm{Kg} /$ ton), Boron $(0,01 \mathrm{Kg} /$ ton $)$ dan Tembaga $(0,01 \mathrm{Kg} /$ ton$)$.

\section{METODE PENELITIAN}

Pelaksanaan penelitian dilaksanakan di Jalan Mensiku Jaya, Komplek BTN Dara Juanti, Kelurahan Ulak Jaya, Menyumbung, Kabupaten Sintang dengan memanfaatkan lahan kosong di samping rumah sebagai tempat penelitian. Penelitian berlangsung selama 90 hari termasuk dalam penyemaian bibit cabai rawit (Capsicum frutescens $L$ ). Parameter yang diamati adalah produktivitas berat basah buah (C.frutescens L.).

Penelitian ini menggunakan metode eksperimen dengan Rancangan Acak Lengkap (RAL) dengan melakukan pengujian pupuk organik berbahan dasar H.verticillata L., dan kotoran ayam dengan perlakuan 0 gram 200 gram, 300 gram, 400 gram dan 500 gram, dan di ulang sebanyak 5 kali. Rancangan penelitian yang akan dilakukan peneliti termuat pada Tabel 1.

Tabel 1. Pupuk Organik Berbahan Dasar H.verticillata L., dan Kotoran Ayam

\begin{tabular}{cccccc}
\hline Perlakuan & \multicolumn{5}{c}{ Ulangan } \\
\cline { 2 - 6 } & U1 & U2 & U3 & U4 & U5 \\
\hline P1 & P1U1 & H1U2 & H1U3 & H1U4 & H1U5 \\
P2 & P2U1 & H2U2 & H2U3 & H2U4 & H2U5 \\
P3 & P3U1 & H3U2 & H3U3 & H3U4 & H3U5 \\
P4 & P4U1 & H2U2 & H4U3 & H4U4 & H4U5 \\
P5 & P5U1 & H3U2 & H5U3 & H5U4 & H5U5 \\
\hline
\end{tabular}

Keterangan:

P1 (Kontrol 1) = H.verticillata L., dan Kotoran Ayam 0 gram (kontrol) $\quad$ U1 = Ulangan 1 
P2 $($ Perlakuan 2) $=$ H.verticillata L., dan Kotoran Ayam 200 gram

P3 (Perlakuan 3) = H.verticillata L., dan Kotoran Ayam 300 gram

P4 (Perlakuan 4) = H.verticillata L., dan Kotoran Ayam 400 gram

P5 $($ Perlakuan 5) = H.verticillata L., dan Kotoran Ayam 500 gram
$\mathrm{U} 2$ = Ulangan 2

$\mathrm{U} 3=$ Ulangan 3

$\mathrm{U} 4$ = Ulangan 4

U5 = Ulangan 5

Alat yang digunakan untuk membuat pupuk organik berbahan dasar H.verticillata L., dan kotoran ayam dapat dilihat pada Tabel 2.

Tabel 2. Alat yang Digunakan untuk Membuat Pupuk Organik dan Kegunaannya

\begin{tabular}{lll}
\hline No & Alat & \multicolumn{1}{c}{ Kegunaan } \\
\hline a) & Tong & Sebagai wadah kompos saat fermentasi \\
b) & Parang & $\begin{array}{l}\text { Untuk mencacah tumbuhan H.verticillata L., menjadi } \\
\text { bagian yang lebih kecil }\end{array}$ \\
c) & Terpal & $\begin{array}{l}\text { Sebagai alas kotoran ayam dan H.verticillata L., saat } \\
\text { dikeringan. }\end{array}$ \\
\hline
\end{tabular}

Bahan yang digunakan untuk membuat pupuk organik berbahan dasar H.verticillata L., dan kotoran ayam dapat dilihat pada Tabel 3.

Tabel 3. Bahan yang Digunakan untuk Membuat Pupuk Organik dan Kegunaannya

\begin{tabular}{|c|c|c|}
\hline No & Nama Bahan & Kegunaan \\
\hline 1) & Nasi bekas & $\begin{array}{l}\text { Bahan utama untuk membuat } \\
\text { (Microorganisme Local) }\end{array}$ \\
\hline 2) & Gula merah & $\begin{array}{l}\text { Bahan tambahan untuk membuat MOL } \\
\text { (Microorganisme Local) }\end{array}$ \\
\hline 3) & Air kelapa & $\begin{array}{l}\text { Sebagai nutrisi bagi mikroba pada saat Fermentasi. } \\
\text { Bahan tambahan untuk membuat MOL } \\
\text { (Microorganisme Local) } \\
\text { Sebagai nutrisi bagi mikroba pada saat Fermentasi }\end{array}$ \\
\hline 4) & Air & $\begin{array}{l}\text { Sebagai pelarut dalam pembuatan MOL } \\
\text { (Microorganisme Local) }\end{array}$ \\
\hline 5) & Tumbuhan Hydrilla verticillata L. & $\begin{array}{l}\text { Sebagai bahan pupuk kompos yang akan } \\
\text { dikombinasikan dengan kotoran ayam. }\end{array}$ \\
\hline
\end{tabular}

Langkah pertama dalam penelitian ini adalah melakukan pengomposan H.verticillata L., dan kotoran ayam dengan menggunakan bantuan starter berupa mikroorganisme lokal (MOL) dari nasi bekas. Sebelum dikomposkan H.verticillata L., dan kotoran ayam di keringkan dibawah terik matahari agar kadar air didalamnya berkurang. Setelah dikeringkan H.verticillata L., dan kotoran ayam ditimbang dengan perbandingan berat H.verticillata $\mathrm{L}$., $7 \mathrm{Kg}$ dan kotoran ayam sebanyak $3 \mathrm{Kg}$. Langkah kedua adalah mencampurkan H.verticillata L., dan kotoran ayam menjadi satu dan diberikan cairan starter (MOL). Cairan starter yang digunakan sebanyak 1 liter dengan ditambahkan air sebanyak 5 liter. Campuran H.verticillata L., dan kotoran ayam yang sudah diberi starter kemudian dimasukan kedalam ember untuk dikomposkan. Langkah ketiga adalah pembuatan area penyemaian bibit tanaman cabai rawit (C. frutescens L.) dengan membuat media semai menggunakan daun pisang tua yang dibentuk melingkar dengan ukuran lebar dan tinggi $3 \times 3 \mathrm{~cm}$. Selanjutnya, peneliti membuat lahan dan tempat seluas $5 \times 3 \mathrm{~m}^{2}$ untuk penanaman dan penyimpanan 25 polybag cabai rawit $(C$. frutescens L.). Setelah menyiapkan tempat penelitian, peneliti mempersiapkan media tanam yang terdiri dari campuran tanah dengan pupuk kompos H.verticillata L., dan kotoran ayam. Tanah dan pupuk kompos ditimbang dan ditakar sesuai dengan perlakuan yang telah ditentukan pada 
Benediktus Ege., Hendrikus Julung. Produktivitas,Tanaman cabai rawi, Hydrilla verticillata $\mathrm{L}$, kotoran ayam

masing-masing polybag yang berukuran $3 \mathrm{Kg}$. Media tanam yang sudah siap ini dibiarkan selama 3 hari agar kondisi tanah dan pupuk menjadi stabil.

Penghitungan untuk jumlah buah dilakukan pada 30, 40, dan 50 hari setelah tanam cabai rawit (C. frutescens L.). Kemudian, saat cabai rawit (C. frutescens L.) berusia 50 hari setelah tanam, peneliti menghitung dan mengamati berat basah buah cabai rawit (C. frutescens L.).

\section{HASIL PENELITIAN}

Hasil yang diperoleh dalam penelitian ini merupakan semua data yang dikumpulkan selama penelitian di lapangan. Berdasarkan hasil analisis deskriptif, jumlah berat basah buah tanaman cabai rawit (C. frutescens L.) menunjukkan hasil yang berbeda-beda pada masingmasing perlakuan. Nilai berat basah buah cabai rawit (C. frutescens L.) tertinggi pada perlakuan ke-5 adalah 104 gram, kemudian pada perlakuan ke-4 berat basah buah tertinggi 90. Perlakuan ke-3 berat basah buah tertinggi adalah 75 gram, kemudian berat basah buah pada perlakuan ke-2 adalah 69, dan pada perlakuan ke-1 adalah 51 gram. Hasil pengukuran berat basah buah tanaman cabai rawit (C. frutescens L.) yang paling banyak secara keseluruhan terdapat pada perlakuan kelima ulangan kedua yaitu dengan takaran 500 gram pupuk organik berbahan dasar H.verticillata L., dan kotoran ayam dengan jumlah 104 gram. Sementara itu,berat basah buah cabai rawit (C. frutescens L.) yang paling rendah secara keseluruhan terdapat pada perlakuan pertama ulangan ketiga yaitu takaran 0 gram pupuk organik berbahan dasar H.verticillata L., dan kotoran ayam dengan jumlah 11 gram. Selanjutnya hasil analisis sidik ragam (Ansira) terhadap berat basah tanaman cabai rawit $(C$. frutescens L.) setelah diberikan pupuk organik berbahan dasar H.verticillata L., dan kotoran ayam yang dihitung pada hari ke-50 setelah tanam dapat dilihat pada Tabel 4 .

Tabel 4. Analisis Sidik Ragam Berat Basah Buah Tanaman Cabai Rawit (C. frutescens L.)

\begin{tabular}{lccccc}
\hline Sumber keragaman & $\begin{array}{c}\text { Derajat } \\
\text { Bebas }\end{array}$ & $\begin{array}{c}\text { Jumlah } \\
\text { kuadrat }\end{array}$ & $\begin{array}{c}\text { Kuadrat } \\
\text { Tengah }\end{array}$ & $\mathrm{F}_{\text {hitung }}$ & $\mathrm{F}_{\text {tabel }}$ \\
\hline Perlakuan & 4 & 9389,04 & 2347,3 & 10,6 & 2,67 \\
galat & 20 & 4429,2 & 221,5 & & \\
\hline Total & 24 & & & & \\
\hline
\end{tabular}

Hasil analisis sidik ragam pada Tabel 4 menunjukkan bahwa produktivitas tanaman cabai rawit (C. frutescens L.) signifikan dipengaruhi oleh pupuk organik berbahan dasar H.verticillata L., dan kotoran ayam dengan $f_{\text {hitung }}>f_{\text {tabel }}(10,6>2,67)$. Selanjutnya, hasil uji beda nyata jujur (BNJ) dapat dilihat pada Tabel 5.

Tabel 5. Uji BNJ Pupuk Organik Berbahan Dasar H.verticillata L., dan Kotoran Ayam terhadap Produktivitas (Berat Basah Buah Tanaman Cabai Rawit)

\begin{tabular}{|c|c|c|c|c|c|c|}
\hline Perlakuan & Rerata & & & Selis & Rerata & \\
\hline$P_{1}=0$ gram & 25,4 & - & & & & \\
\hline$P_{2}=2$ gram & 46 & $20,6^{\mathrm{Tn}}$ & & & & \\
\hline$P_{3}=3$ gram & 54,8 & $29,4^{*}$ & $8,8^{\mathrm{Tn}}$ & & & \\
\hline$P_{4}=4$ gram & 70 & $44,6^{*}$ & $24^{\mathrm{Tn}}$ & $15,2^{\mathrm{Tn}}$ & & \\
\hline$P_{5}=5$ gram & 81,4 & $56^{*}$ & $35,4^{*}$ & $26,6^{\mathrm{Tn}}$ & $11,4^{\mathrm{Tn}}$ & - \\
\hline
\end{tabular}

Keterangan $:{ }^{*}=$ nyata $_{\mathrm{n}}=$ Tidak nyata 
Berdasarkkan hasil uji BNJ tersebut, menunjukan bahwa kelompok yang diberi berlakuan dengan takaran 500 gram pupuk organik berbahan dasar H.verticillata L., dan kotoran ayam memberikan hasil yang optimum terhadap produktivitas (berat basah) tanaman cabai rawit (C. frutescens L.) yaitu dengan rata-rata 81,4 gram.

\section{PEMBAHASAN}

Hasil pengamatan pengaruh pupuk organik berbahan dasar H.verticillata L., dan kotoran ayam terhadap produktivitas tanaman cabai rawit (C. frutescens L.) setelah 50 hari menunjukkan bahwa terdapat pengaruh nyata terhadap produktivitas yang ditandai dengan perbedaan berat basah buah cabai rawit (C. frutescens L.) pada masing-masing perlakuan. Adapun berat buah pada masing-masing perlakuan yang tertinggi yaitu P1 adalah 51 gram, P2 adalah 75 gram, P3 adalah 69 gram P4 adalah 90 gram dan P5 adalah 104 gram.Tanaman cabai rawit yang diberi perlakuan pupuk tertinggi yaitu 500 gram pupuk organik berbahan dasar H.verticillata L., dan kotoran ayam menghasilkan berat buah yang tinggi bila dibandingkan dengan perlakuan yang tidak diberi perlakuan pupuk organik.

Perbedaan berat basah buah cabai rawit (C. frutescens L.) dikarenakan adanya pemberian kombinasi H.verticillata L., dan kotoran ayam, dimana H.verticillata L., merupakan bahan pupuk organik yang sebagian besar mengandung unsur hara mikro dan kotoran ayam lebih didominasi kandungan unsur hara makro sehingga kebutuhan unsur hara tanaman cabai rawit (C. frutescens L.) menjadi lengkap dan seimbang. H.verticillata L., mengandung mineral dan nutrien yaitu kalsium magnesium, potassium, fosfor, besi, seng, mangan, tembaga, kobalt, molibdenum, dan $\beta$-karoten (Pal dan Nimse, 2006). Selain itu, jumlah dosis pupuk organik juga berpengaruh sehingga harus disesuaikan dengan jenis dan kebutuhan tanaman. Unsur potassium atau kalium sangat diperlukan dalam perkembangan buah cabai terutama pada saat buah cabai sedang membesar. Pada fase pembentukan bunga dan buah unsur fosfor sangat penting karena berperan membawa air ke sel-sel sehingga buah dapat berkembang dengan baik.

Produktivitas tanaman yang diharapkan dapat dicapai apabila jumlah dan macam unsur hara di dalam tanah bagi pertumbuhan tanaman berada dalam keadaan cukup, seimbang, dan tersedia sesuai kebutuhan tanaman (Nurlenawati, dkk., 2010: 19). Struktur tanah yang baik menjadikan perakaran berkembang dengan baik sehingga semakin luas bidang serapan terhadap unsur hara maka dapat menjadikan tanaman cabai mampu berproduktivitas dengan baik (Notohadiprawiro, dkk, 2006). Menurut Ibrahim (2012), kurangnya unsur hara dalam tanah dapat berakibat rendahnya produktivitas pada cabai rawit. Jika unsur hara dalam tanah tidak tersedia maka pertumbuhan tanaman akan terhambat dan produksinya menurun. Kekurangan salah satu atau beberapa unsur hara akan mengakibatkan pertumbuhan tanaman tidak sebagaimana mestinya yaitu ada kelainan atau penyimpangan-penyimpangan dan banyak pula tanaman yang mati muda (Thania, 2011).

Letak tanaman cabai rawit juga menjadi salah satu faktor yang mempengaruhi produktivitas tanaman cabai rawit karena pada saat penelitian tanaman yang tidak diberi pupuk organik (kontrol) lebih sering terserang hama dan penyakit, sehingga tanaman yang berdekatan dengan tanaman kontrol akan terserang hama dan penyakit juga. Tanaman cabai rawit yang terletak dekat dengan dengan tanaman yang berbuah cepat akan ada kemungkinan berbuah cepat pula karena adanya penyerbukan pada bunga yang dilakukan oleh serangga 
disekeliling tanaman tersebut. Perbandingan produktivitas tanaman cabai rawit dapat dilihat pada Gambar 2.

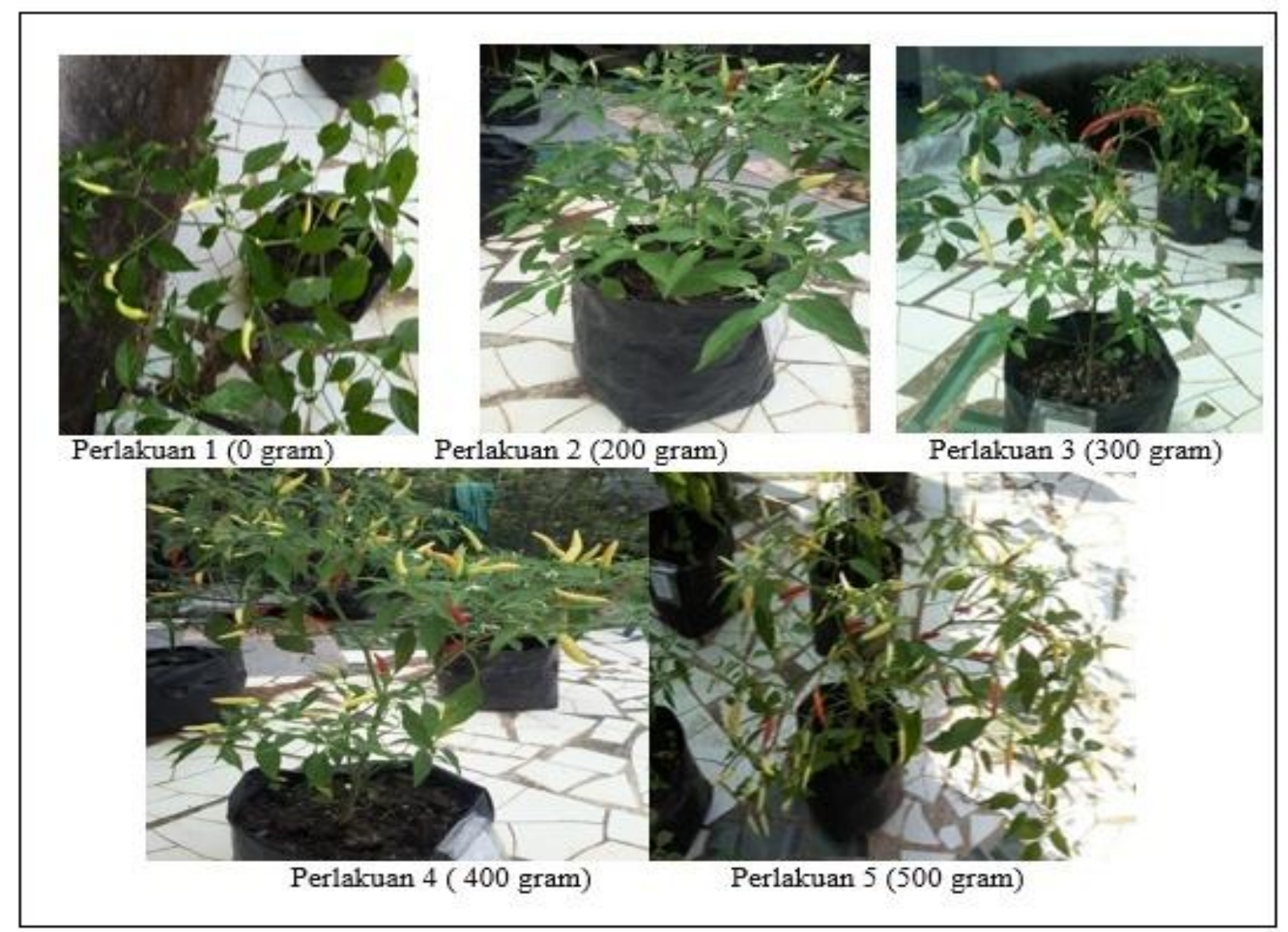

Gambar 2. Perbandingan Produktivitas Tanaman Cabai Rawit (Capsicum frutescens L) Pada MasingMasing Perlakuan

\section{SIMPULAN}

Hasil penelitian dengan pemupukan menggunakan pupuk organik berbahan dasar H.verticillata L., dan kotoran ayam berdasarkan rerata produktivitas yaitu berat basah buah menunjukkan bahwa terdapat perbedaan yang signifikan pada masing-masing perlakuan dimana berat basah buah cabai rawit (C. frutescens L.) dalam satu tanaman tertinggi adalah 104 gram yaitu pada P5 (takaran 500 gram) dan berat basah terendah adalah P1 (tanpa perlakuan) yaitu 51 gram. Berdasarkan hasil uji ansira menunjukkan $f_{\text {hitung }}>f_{\text {tabel }}$ pada parameter produktivitas sehingga perlakuan pupuk organik berbahan dasar H.verticillata L., dan kotoran ayam berpengaruh nyata terhadap produktivitas tanaman cabai rawit (C. frutescens L.). Berdasarkan uji lanjutan yaitu BNT pada parameter produktivitas (berat basah buah) menunjukkan bahwa produktivitas tanaman cabai rawit (C. frutescens L.) yang paling optimal terdapat pada perlakuan ke-5 dengan takaran 500 gram pupuk organik berbahan dasar H.verticillata L., dan kotoran ayam. 


\section{SARAN}

Pemberian pupuk organik berbahan dasar Hydrilla verticillata L., dan kotoran ayam dapat menjadi referensi dalam meningkatkan pertumbuhan dan produktivitas tanaman cabai rawit (Capsicum frutescens L). Penelitian selanjutnya agar melakukan penelitian dengan perlakuan, jenis tanah (media) dan tempat yang berbeda. Penelitian selanjutnya agar menggunakan takaran pupuk yang berbeda atau ditambahkan dosis yang lebih tinggi untuk mendapatkan hasil yang paling optimal.

\section{UCAPAN TERIMA KASIH}

Penulis mengucapkan terima kasih kepada Direktorat Riset dan Pengabdian Masyarakat Direktorat Jenderal Penguatan Riset dan Pengembangan Kementerian Riset, Teknologi, dan Pendidikan Tinggi yang telah memberikan dukungan financial terhadap penelitian ini dengan nomor kontrak: 04/L-2/Penelitian.STKIP-PK/IV/2019. Penulis juga mengucapkan terimakasih kepada pembantu peneliti pada saat proses pengumpulan data baik di laboratorium maupun di lapangan.

\section{DAFTAR PUSTAKA}

Arifah, M S. 2013. Aplikasi Macam Dan Dosis Pupuk Kandang Pada Tanaman Kentang. Jurnal Gamma. Universitas Muhamadiyah Malang.

Badan Pusat Statistik dan Direktorat Jenderal Hortikulutura. 2019. Rata-rata Konsumsi Per Kapita Seminggu Beberapa Macam Bahan Makanan Penting, 2007-2018. https://www.bps.go.id/statictable/2014/09/08/950/rata-rata-konsumsi-per-kapitaseminggu-beberapa-macam-bahan-makanan-penting-2007-2018.html. Diakses tanggal 19 Juli

Darmawan, I. G. P., I. D. N. Nyana dan I. G. A. Gunadi. 2014. Pengaruh Penggunaan Mulsa Plastik terhadap hasil tanaman cabai rawit (Capsicum frutescens L.) di luar musim di desa Kerta. Jurnal Agroteknologi Tropika. 3(3):148-157

Hanafiah, Kemas. 2014. Rancangan Percobaan Teori E. Aplikasi. Jakarta. Rajagrafindo Persada

Ibrahim. 2012. http://petunjukbudidaya.blogspot.com/2012/12/defisiensi-unsur-hara.html. Diakses 13 Januari 2019.

Kusumawati, R.D., Didik, H., Nurul, A. 2016. Pengaruh Komposisi Media Tanam dan Interval Pemberian Air sampai dengan Kapasitas Lapang terhadap Produksi Tanaman Cabai Rawit (Capsicum frutescens L.). Plantropica Journal of Agricultural Science 1(2):64-71. https://jpt.ub.ac.id/index.php/jpt/article/view/118. Diakses tanggal 18 Juli 2019.

Marwan, et al. 2017. “Pemanfaatan Hydrilla Verticillata(L.F.) Royle Sebagai Pupuk Hijau Untuk Memacu Pertumbuhan Bibit Kakao (Theobroma CacaoL.)".Palopo Sulawesi Selatan. Journal Tabaro.

Nurlenawati, N., Jannah, Asmanur.,Nimih. 2010. Respon Pertumbuhan dan Hasil Tanaman Cabai Merah (Capsicum annum L.) varietas prabu terhadap berbagai dosis pupuk fosfat dan bokashi jerami limbah jamur merang. AGRIKA. Vol. 3 Nomor 1: 9-20

Notohadiprawiro, Soeprapto dan E. Susilowati. 2006. Pengelolaan Kesuburan Tanah dan Efisiensi PemupukanYogyakarta: Ilmu Tanah UGM

Pal dan Nimse. 2006.Little known uses of common aquatic plant, Hydrilla verticillata (Linn. f.) Royle.India.Natural Products Research Laboratory, Department of Pharmaceutical Chemistry Seemanta Institute of Pharmaceutical Sciences. Jharpokharia Mayurbhan 
Benediktus Ege., Hendrikus Julung. Produktivitas,Tanaman cabai rawi, Hydrilla verticillata $\mathrm{L}$, kotoran ayam

Umah, Khoiru.2012. “Pengaruh Pemberian Pupuk Hayati (Biofertilizer) Dan Media Tanam Yang Berbeda Pada Pertumbuhan Dan Produktivitas Tanaman Cabai Rawit (Capsicum Frutescens L.) Di Polybag".ADLN Perpustakaan Universitas Airlangga.

Simanungkalit,dkk.2006.Pupuk Organik Dan Pupuk Hayati. Jawa barat. Balai Besar Penelitian dan Pengembangan Sumberdaya Lahan Pertanian.

Suwahyono, Untung. 2014. Cara Capat Buat Kompos dari Limbah. Jakarta. Penebar Swadaya.

Thania. 2011. http://tha.co.id/berita-3-akibat-kekurangan-salah-satu-unsur-hara.html. Diakses 13 Januari 2019. 